\title{
Clinical application of psychotherapy in nursing patients with
}

\section{esophageal cancer}

\section{Liu Jiajia}

Department of Radiation Therapy, People’s Hospital of Inner Mongolia Autonomous Region, Hohhot 010017

\section{ARTICLE INFO}

Article history:

Published online: 15th July, 2017

Key words:

Esophageal cancer

psychotherapy

nursing

\section{Materials and methods}

A total of 100 elderly patients with chronic diseases were enrolled in our hospital from January 2016 to January 2017. They were randomly divided into observation group and control group. There were 21 males and 29 females aged $25 \sim 65$ years old, the

\section{ABSTRACT}

Objective: To evaluate the clinical application of psychotherapy in the nursing center of patients with esophageal cancer. Methods: 100 patients with esophageal cancer treated in our hospital from January 2016 to January 2017 were randomly divided into observation group and control group. Fifty patients in each group were treated with routine rehabilitation. On treatment wise, observation group to take psychological treatment, compared between the two groups before and after treatment of anxiety, depression score, quality of life and $\mathrm{CD}^{+}, \mathrm{CD}^{+}$, $\mathrm{CD}^{+}$and other indicators. Results: The scores of depression and anxiety in the observation group were significantly lower than those in the control group $(\mathrm{P}<0.05)$. The $\mathrm{CD}^{+}, \mathrm{CD}^{+}$ and $\mathrm{CD} 8^{+}$were significantly higher in the two groups after treatment in compare with before treatment, the difference was statistically significant $(\mathrm{P}<0.05)$. Conclusion: Through psychological treatment, it can effectively improve the situation of patients with esophageal cancer, so that the quality of life of patients has been significantly improved, with high efficiency 
significantly $(\mathrm{P}>0.05)$. This study, through the consent of the Hospital Ethics Committee, all patients are informed of this study, and signed informed consent.

\subsection{Methods}

1.2.1 Control group: the patient for routine rehabilitation counseling, review, exercise and drug rehabilitation treatment.

1.2.2 Observation group: in the control group based on psychological treatment. First, before the treatment of 1 day to 3 days after treatment to the patient's state to have a detailed understanding, and then to the patient about a good attitude on the treatment of the effect, while allowing patients to understand the way of psychological treatment and timing arrangement issues. Second, within 14 days of treatment, the caregiver should tell the patient about the knowledge associated with esophageal cancer. Allowing the patient to understand the negative emotions of the risk of esophageal cancer. Again, after 14 to 20 days of treatment, nurses to the patient's psychological intervention, which making patients with esophageal cancer have a clear understanding, to guide patients to vent their emotions, and exchange of psychological feelings of mutual exchange. Fourth, 21 days to 28 days after treatment, nurses want vaginal patients to discuss the exchange and fear of esophageal cancer, so that the man can re-face the meaning of life, encourage patients to challenge life, so as to improve the quality of life. Finally, after 28 to 55 days of treatment, the caregiver guides the patient in changing the physical condition and mental state of the sick and encourages the patient to form a good habit of self-expression, consolidating the outcome of the treatment, so that patients can actively treat parting emotions

The scores of anxiety, depression, quality of life and $\mathrm{CD}^{+}, \mathrm{CD}^{+}, \mathrm{CD}^{+}{ }^{+}$were compared between the two groups before and after treatment. Anxiety and depression were based on the self-rating anxiety scale and depression self-rating scale.

\subsection{Statistical analysis}

The data collected by SPSS18.0 software for statistical analysis, with the test count data, measurement data are used ( $\overline{\mathrm{x}} \pm \mathrm{s})$, to $t$ test to $\mathrm{P}<0.05$ for the difference was statistically significant.

\section{Results}

\subsection{Comparison of anxiety and depression scores between the two groups before and after treatment}

After treatment, the anxiety and depression of the observation group were significantly better than those in the control group, the difference was statistically significant $(\mathrm{P}<0.05)$. See Table 1 .

\subsection{Comparison of $\mathrm{CD3}^{+}, \mathrm{CD}^{+}$and $\mathrm{CD8}^{+}$levels between the two groups before and after treat- ment}

After treatment, the two groups of patients to be significantly better than the situation before treatment, the difference was statistically significant $(\mathrm{P}<0.05)$. See

Table 1 Comparison of anxiety and depression scores between the two groups before and

\begin{tabular}{lccccc}
\hline \multirow{2}{*}{ Group } & & \multicolumn{2}{c}{ Anxiety score } & \multicolumn{2}{c}{ Depression score } \\
& & Before treatment & After treatment & Before treatment & After treatment \\
\hline $\begin{array}{l}\text { Observation } \\
(\mathrm{n}=50)\end{array}$ & group & $44.85 \pm 5.89$ & $33.67 \pm 4.38$ & $44.96 \pm 5.56$ & $32.91 \pm 4.62$ \\
$\begin{array}{l}\text { Control } \\
(\mathrm{n}=50)\end{array}$ & group & $44.88 \pm 5.67$ & $43.25 \pm 5.32$ & $44.97 \pm 5.46$ & $42.77 \pm 5.64$ \\
\hline
\end{tabular}

Table 2 Two groups of patients before and after treatment $\mathrm{CD} 3^{+}, \mathrm{CD} 4^{+}, \mathrm{CD} 8^{+}$levels

\begin{tabular}{lcccccc}
\hline \multicolumn{2}{c}{} & \multicolumn{2}{c}{$\mathrm{CD}^{+}$} & \multicolumn{2}{c}{$\mathrm{CD}^{+}$} & \multicolumn{2}{c}{$\mathrm{CD}^{+}$} \\
Group & $\begin{array}{c}\text { Before } \\
\text { treatment }\end{array}$ & $\begin{array}{c}\text { After treat- } \\
\text { ment }\end{array}$ & $\begin{array}{c}\text { Before } \\
\text { treatment }\end{array}$ & $\begin{array}{c}\text { After treat- } \\
\text { ment }\end{array}$ & $\begin{array}{c}\text { Before treat- } \\
\text { ment }\end{array}$ & After treatment \\
\hline $\begin{array}{l}\text { Observation } \\
\text { group (n=50) }\end{array}$ & $0.85 \pm 0.09$ & $0.61 \pm 0.08$ & $0.36 \pm 0.07$ & $0.51 \pm 0.06$ & $0.32 \pm 0.05$ & $0.23 \pm 0.07$ \\
\hline $\begin{array}{l}\text { C o n t r o 1 } \\
\text { group (n=50) }\end{array}$ & $0.88 \pm 0.07$ & $0.55 \pm 0.08$ & $0.36 \pm 0.07$ & $0.47 \pm 0.06$ & $0.33 \pm 0.06$ & $0.30 \pm 0.06$ \\
\hline
\end{tabular}


Table 2.

\section{Discussion}

Esophageal cancer mortality is relatively high, many patients will be cancer and death linked together, so that patients cannot afford to bear physical and psychological pain, which will produce anxiety, depression, at the same time, The physiological treatment and treatment of compliance caused a greater impact. The degree of anxiety and depression has a greater correlation to their cognition, and in the long term in a bad mood, the patient's immune system will be reduced.

In order to reduce the psychological pressure of patients, we should listen to the psychological pressure of patients, many patients with esophageal cancer want to have a clear understanding of esophageal cancer, by telling their own situation, to alleviate the negative emotions. As in the daily circumstances, many patients have no way to tell their own situation, so that there is no way to release the heart pressure, through psychological treatment, can effectively alleviate the patient's situation, allowing patients to form a good attitude, a correct view of the disease.

\section{References:}

[1] Song Baoguo. Esophageal Cancer After Radiotherapy Combined with Traditional Chinese Medicine Treatment Of Psychological Effects [J]. Chinese and foreign medical research, 2013, (20): 13-13,14.

[2] Yuan Xiaohong. Esophageal Cancer Patients Before and After the Operation of Anxiety and Nursing Countermeasures [J]. Journal of Nursing, 2001, 16 (4): 240-241.

[3] Tang Hong. Esophageal Cancer Patients with Perioperative Anxiety And Depression And Disease Awareness Of The Degree Of Correlation [J]. Contemporary nurses (mid-term), 2016, (11): 76-77,78. 